Fedele, D.A., Lefler, E.K., Hartung, C.M., \& Canu, W.H. (2012). Sex Differences in the Manifestation of ADHD in Emerging Adults. Journal of Attention Disorders, 16(2): 109-117 (Feb 2012). Published by SAGE (ISSN: 15571246).

\title{
Sex Differences in the Manifestation of ADHD in Emerging Adults
}

David A. Fedele, Elizabeth K. Lefler, Cynthia M. Hartung, and Will H. Canu

\begin{abstract}
Objective: Given the mixed literature in the area, the aim of the current study was to determine whether sex differences exist in inattention, hyperactivity, and impairment in college adults with ADHD. Method: Individuals from three universities were recruited for the study. Participants with $(n=164)$ and without $\operatorname{ADHD}(n=710)$ completed on-line measures of symptoms and impairment. Results: College women with ADHD were shown to have higher rates of inattention, hyperactivity, and impairment than college women without ADHD and college men with ADHD. Analyses revealed that women in college who have ADHD experience higher levels of impairment in the following domains: home life, social life, education, money management, and daily life activities. Conclusion: Overall, clear differences emerged between men and women with ADHD. Implications and future directions are discussed.
\end{abstract}


ADHD (American Psychiatric Association [APA], 2000) is defined as developmentally inappropriate inattentive, hyperactive, or impulsive behavior. Although ADHD was once conceptualized as a disorder of childhood and adolescence (Wender, 1987), it has been shown to persist in many cases. In fact, longitudinal studies examining the persistence of ADHD in both emerging and typical adults have demonstrated impairment across the lifespan (Fischer, Barkley, Edelbrock, \& Smallish, 1990; Gittelman, Mannuzza, Shenker, \& Bonagura, 1985; Manuzza, Klein, Bessler, Malloy, \& LaPadula 1993; Weiss \& Hechtman, 1993), suggesting that approximately $70 \%$ of individuals diagnosed as children experience impairment into adulthood (Weiss, Hechtman, Milroy, \& Perlman, 1985). Overall, prevalence estimates for ADHD in adults range from $3.5 \%$ to $4.5 \%$ make it a relatively common adult disorder (Faraone \& Biederman, 2005; Kessler et al., 2006; Murphy \& Barkley, 1996). Such findings, along with studies that emphasize the genetic-familial nature of ADHD (Biederman, Faraone, Mick, \& Spencer, 1995; Faraone, Biederman, Feighner, \& Monuteaux, 2000; Manshadi, Lippman, O'Daniel, \& Blackman, 1983), lend support to the notion that this syndrome remains valid in the adult population.

In addition, empirical research suggests that adults with ADHD symptoms experience pervasive impairment in several domains, including success and safety at work (Biederman et al., 2006; de Graaf et al., 2008; Kessler, Lane, Stang, \& Van Brunt, 2009), interpersonal relationships (Biederman et al., 2006; Canu \& Carlson, 2003; Weiss et al., 1985), executive functioning (Barkley, Murphy, \& Kwasnik, 1996; MalloyDiniz, Fuentes, Leite, Correa, \& Bechara, 2007; Murphy, Barkley, \& Bush, 2001), academic outcomes (Heiligenstein, Conyers, Berns, \& Miller, 1998; Lewandowski, Lovett, Codding, \& Gordon, 2008; Schwanz, Palm, \& Brallier, 2007), and general life satisfaction (Biederman et al., 2006). Finally, comorbidity in adults diagnosed with ADHD has been well documented, as individuals with ADHD have higher prevalence rates of mood, anxiety, eating, and substance disorders than nondiagnosed peers (Biederman, Faraone, Monuteaux, Bober, \& Cadogen, 2004; Sobanski et al., 2007).

\section{SEX DIFFERENCES IN ADULT ADHD}

Unfortunately, an area that has not received sufficient attention in this growing body of adult ADHD literature is sex differences in symptom manifestation and impairment. With regard to child and adolescent ADHD, existent research suggests that ADHD is diagnosed more often in boys than girls, with male to female ratios ranging from $2: 1$ to $3: 1$ in community samples (APA, 2000, Bauermeister et al., 2007; Rucklidge, 
2008). However, it appears that this sex difference in ADHD found in child and adolescent samples is smaller or nonexistent in adults. For example, Biederman and colleagues (2004) demonstrated that adult men and women did not differ in phenotypic expression of ADHD, suggesting that there were sex differences in neither lifetime inattentive, hyperactive, or total ADHD symptom scores nor current hyperactive or total ADHD symptoms scores. The only difference found in this study was in self-reported inattention, such that women reported higher symptom levels than did men. Another large multinational study similarly revealed that young men and women did not differ in total number of self-reported inattention and hyperactivity symptoms (DuPaul et al., 2001). Other research has yielded similar findings (e.g., Biedereman et al., 2005; Murphy \& Barkley, 1996).

While this converging evidence suggests that total symptoms of ADHD appear to be approximately equal in adult men and women, it remains unclear whether ADHD-related impairment impacts adult men and women differently. Therefore, research examining potential sex differences in impairment is needed, especially considering that ADHD-related impairment has been shown to affect multiple domains of adult functioning (see earlier). Also, because impairment and symptom levels have been found to be separable and independent (Gathje, Lewandowski, \& Gordon, 2008), it is conceivable that there could be sex differences in symptoms but not impairment, or vice versa. Another reason it is compelling to examine sex differences in impairment is the finding that subjective impairment is often the catalyst for referral (Gordon et al., 2008). Finally, there is a growing body of research to suggest that adult men and women with ADHD have differential neuropsychological markers (Hermens et al., 2004; Seidman, et al., 2004), which suggests the possibility of sexspecific etiologies and consequent behavioral manifestations of ADHD.

The predominant theme of existing literature on sex differences in adult ADHD pertains mainly to comorbidity. For example, studies examining typical adults have demonstrated that men with ADHD have higher rates of antisocial personality disorder, conduct disorder, and substance abuse than women with ADHD (Biederman et al., 2004), whereas women with ADHD endorse higher levels of mood disorders, eating disorders, and sleep problems (Rasmussen \& Levander, 2009; Robison et al., 2008; Sobanski et al., 2007). It should be noted, however, that several of these disorders are known to have similarly biased prevalence rates by sex regardless of ADHD diagnosis (Hartung \& Widiger, 1998). Relatively few studies have examined sex differences in impairment-related outcome variables. The research that exists suggests that adult 
men and women with ADHD have similar rates of academic, family, and social impairment (Biederman et al., 2004;

Sobanksi et al., 2007), but that women with ADHD report being more emotionally labile (Robison et al., 2008). Additional research beyond comorbidity and symptom expression is warranted to expound upon salient sex differences in adult ADHD.

\section{THE CURRENT STUDY}

What remains undetermined is whether sex differences exist for self-reported impairment domains among individuals, particularly emerging adults in college, with ADHD. The current study has the following three aims: (a) examine whether young adults in college with ADHD differ on Diagnostic and Statistical Manual of Mental Disorders (4th ed., Text Revision.; DSM-IV-TR; APA, 2000) inattention and hyperactivity symptom levels compared to controls, (b) to investigate potential sex differences in impairment of emerging adults in college with ADHD compared to controls, and (c) to examine whether sex accounts for unique variance impairment beyond that accounted for by DSM-IV-TR ADHD symptoms. It was hypothesized that college adults with ADHD would endorse higher levels of inattention, hyperactivity, and subsequent impairment than same-sex controls. Also, it was hypothesized that college men with ADHD would endorse higher levels of inattention and hyperactivity symptoms than would college women with ADHD. It was further hypothesized that college men with ADHD would endorse higher levels of impairment than would college women with ADHD. Finally, it was hypothesized that sex would account for unique variance in impairment beyond that accounted for by DSM-IV-TR ADHD symptoms.

\section{METHOD}

\section{Participants}

Participants in the current study were part of a larger group recruited for another study (Fedele, Hartung, Canu, \& Wilkowski, in press). Participants were students at three universities:

Appalachian State University (ASU), Oklahoma

State University (OSU), and the University of Wyoming (UW). There were 874 total participants. The control group included 710 participants (336 men, 374 women), whereas the ADHD group included 164 participants (72 men, 92 women). Overall, the sample was composed of 300 participants from ASU (113 men, 187 women), 303 from OSU (165 men, 138 women), and 271 from UW (130 men, 141 women). Participants were 
recruited from student disability services, research participant pools, and mental health clinics at the universities. Participants recruited from student disability services and mental health clinics were paid $\$ 10.00$ for study completion, and those recruited from research participant pools received course credit toward an undergraduate psychology course.

The sex composition of the sample for the current study was $53.3 \%$ women $(n=466)$ and $46.7 \%$ men $(n=408)$. The ethnic composition of the sample was $84.8 \%$ European American, 4.1\% African American, 4.0\% Hispanic/Latino, $3.1 \%$ Native American, 1.8\% Asian American, 1.1\% biracial, and $0.7 \%$ other. There was no significant difference in the distribution of ethnicity among sites, $\mathrm{X} 2(1, N=874)=.03, n s$, when ethnicity was coded as European American versus nonEuropean American.

\section{Categorization of Participants into Groups}

Participants who endorsed either a previous ADHD diagnosis or who currently met DSM-IV-TR criteria for ADHD based on self-report were included in the ADHD group. Specifically, 53 participants currently met ADHD criteria and had a previous diagnosis, 69 endorsed a previous diagnosis but did not currently meet full DSM-IV-TR criteria, and 44 currently met $D S M-I V-T R$ criteria but did not report a previous diagnosis. There was no significant difference in the distribution of these categories of ADHD status among sites, $\mathrm{X} 2(4, N=164)=7.55$, $p=.11$. Examination of participants in the ADHD group with a previous DSM-IV-TR diagnosis revealed that $31.9 \%$ ( $n=53$ ) were diagnosed by medical doctors, $16.3 \%(n=27)$ by doctoral-level therapists, and $1.2 \%(n=2)$ by master'slevel therapists. All other participants did not report a diagnostic source. In addition, 60 (36.6\%) participants in the ADHD group reported receiving therapeutic services while 106 (63.4\%) participants denied any psychological or pharmacological treatment history. Participants with comorbid diagnoses were included in the sample, and participants were not excluded for any reason other than incomplete participation.

\section{Measures}

Demographic form. Created for this study, this self-report form included participant's sex, date of birth, ethnicity, mental health treatment history, and date of initial ADHD diagnosis and type of diagnostician (if applicable). 
form includes 18 ADHD and 10 impairment items (Barkley \& Murphy, 2005). Participants rated their behavior over the past 6 months. This rating scale closely parallels $D S M-I V-T R$ (APA, 2000) ADHD criteria and takes approximately 10 minutes to complete. All items required a choice of four responses and summary scores were computed for inattention and hyperactivity symptoms by assigning values of 0 through 3 for Never/Rarely, Sometimes, Often, and Very Often respectively. Cronbach's alpha for inattention and hyperactivity scores were .86 and .84 , respectively.

Impairment form. Impairment items from Barkley's Current and Childhood Symptoms Scale-Self-Report Form measured the degree to which a participant's inattention and hyperactivity symptoms caused problems for them in multiple life domains (e.g., family, work, social, education, relationships, money, driving, recreation, and daily responsibilities) in the past 6 months. Impairment items were administered following the presentation of the DSM-IV-TR ADHD items. Again, all items required a choice of four responses and summary scores were computed by assigning values of 0 through 3 for Never/ Rarely, Sometimes, Often, and Very Often, respectively. Cronbach's alpha for the current sample was .83.

\section{Procedure}

This study was approved by each university's Institutional Review Board and was completed online. Directors of student disability services sent e-mails to students receiving services at OSU and UW. At ASU, the same e-mail was distributed to individuals receiving tutoring services. The e-mail included a brief outline of the study, details about compensation, and a hyperlink to the experiment website. For recruitment via research participant pools, the same brief description was provided on the recruitment website along with the hyperlink. Finally, recruitment flyers were posted in mental health clinics at all three universities.

The first page of the website was the consent form. This page included a description of the purpose of the study, procedure, duration, risks, benefits, and compensation. After complete description of the study to the subjects, informed consent was requested. Following informed consent, the remaining measures were presented in a standardized order (i.e., Demographics Form, Barkley's Current Symptoms Scale, Impairment Form). Finally, a page with debriefing information was displayed. 


\section{Overview of Analyses}

To identify potential covariates, a series of bivariate correlations were conducted with DSM-IV-TR inattention and hyperactivity summary scores, impairment summary score, and demographic variables (i.e., age, ethnicity, years of education, and type of diagnostician) as the independent variables (IVs). Then, in order to delineate potential sex differences in self-reported $D S M-I V-T R$ inattention and hyperactivity symptoms, and impairment, separate 2 (men vs. women) $\times 2$ (ADHD vs. control) ANCOVAs were conducted. As previously discussed, the control group was included to ensure that any potential sex differences in the ADHD group were not reflective of an overall main effect of sex in the entire sample. Notably, post-hoc analyses were conducted to examine any significant interaction. Furthermore, follow-up item-byitem MANCOVA impairment analyses in the ADHD group were conducted to better understand sex differences. Finally, a regression was conducted in the ADHD group to determine if sex accounted for unique variance in impairment above and beyond DSM-IV-TR inattention and hyperactivity symptoms. Specifically, a hierarchical linear regression was conducted with impairment summary scores as the DV and age as a covariate at Step 1. DSM-IV-TR inattention and hyperactivity summary scores were entered at Step 2 and sex was entered at Step 3.

\section{RESULTS}

\section{Preliminary Analyses}

Correlation analyses revealed that age was significantly positively correlated with inattention $r(874)=.18, p<.001$, hyperactivity $r(874)=.11, p=.001$, and impairment $r(874)=.18$, $p<.001$. None of the other demographic variables were significantly correlated with inattention, hyperactivity, or impairment. Therefore, only age was used as a covariate in all subsequent analyses.

\section{Comparison of Inattention Symptoms Across Groups and Sex}

Analysis of covariance (ANCOVA) analyses revealed a significant main effect for group, $F(1,869)=601.74, p<.001$, partial $\eta 2=.41$, such that participants with ADHD $(M=13.07$, $S D=5.69)$ endorsed higher levels of inattention than controls $(M=4.55, S D=3.42)$. There was not a significant main effect for sex, $F(1,869)=1.33, p=n s$. However, the main effects were qualified by a significant sex by group interaction, 
$F(1,869)=32.17, p<.001$, partial $\eta 2=.04$. Therefore, separate ADHD and control group main effects were analyzed post hoc. For the control group, there was a significant main effect for sex, $F(1,707)=37.86, p<.001$, partial $\mathrm{h} 2=.05$, such that women endorsed lower levels of inattention $(M=$ $3.81, S D=2.96)$ than did men $(M=5.37, S D=3.71)$. In contrast, for participants in the ADHD group, there was a significant main effect for sex, $F(1,161)=7.30, p=.008$, partial $\eta 2=.04$, such that women endorsed higher levels of inattention $(M=14.21, S D=6.05)$ than did men $(M=12.00$, $S D=5.03$; see Figure 1).

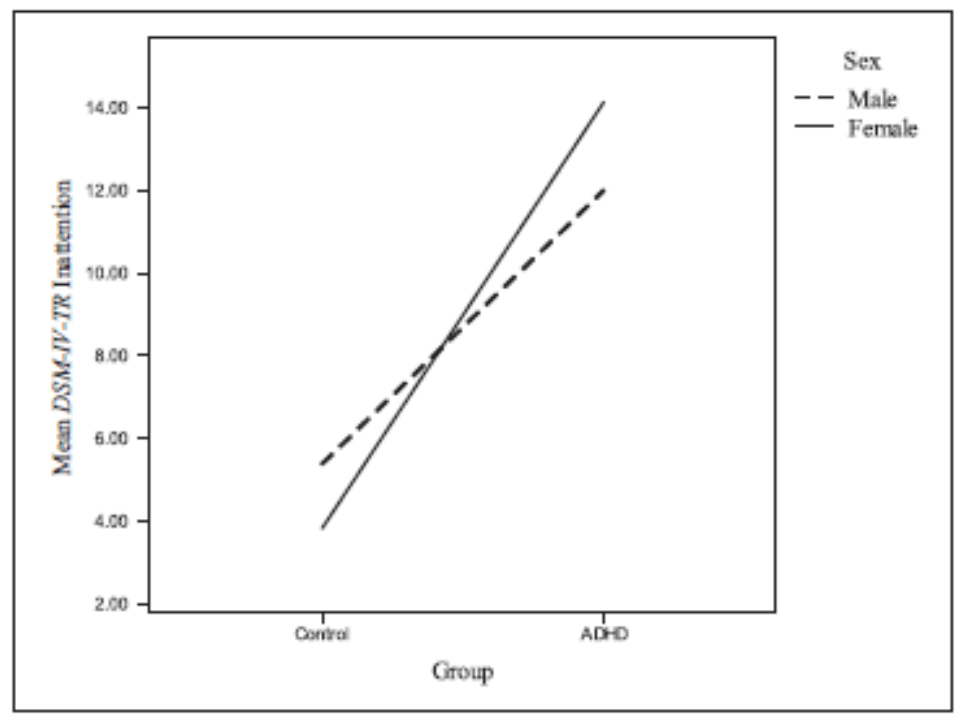

Figure I. Comparison of inattention symptoms DSM-IV-TR = Diagnostic and Statistical Manual of Mental Disorders (4th ed., text revision; APA, 2000).

\section{Comparison of Hyperactivity Symptoms across Groups and Sex}

ANCOVA analyses demonstrated a significant main effect for group, $F(1,869)=525.62, p<.001$, partial $\eta 2=.38$, such that participants with ADHD $(M=12.86, S D=5.46)$ endorsed higher levels of hyperactivity than did controls $(M=$ $5.28, S D=3.18$ ). In addition, there was a significant main effect for sex, $F(1,869)=4.98, p=.026$, partial $\eta 2=.01$, such that women endorsed higher levels of hyperactivity ( $M$ $=6.75, S D=5.09)$ than did men $(M=6.68, S D=4.37)$. However, the main effects were qualified by a significant sex by group interaction, $F(1,869)=15.52, p<.001$, partial $\eta 2=.02$. Post hoc analyses were again conducted to reveal the pattern of data underlying the interaction. For participants 
in the control group, there was a significant main effect for sex, $F(1,707)=5.40, p=.020$, partial $\eta 2=.01$, such that women endorsed lower levels of hyperactivity $(M$ $=5.02, S D=3.01)$ than did men $(M=5.57, S D=3.35)$. In contrast, for participants in the ADHD group, there was a significant main effect for sex, $F(1,161)=5.56, p=.020$, partial n2 $=.03$, such that women endorsed higher levels of hyperactivity $(M=13.79, S D=5.73)$ than did men $(M=$ 11.82, $S D=4.91$; Figure 2).

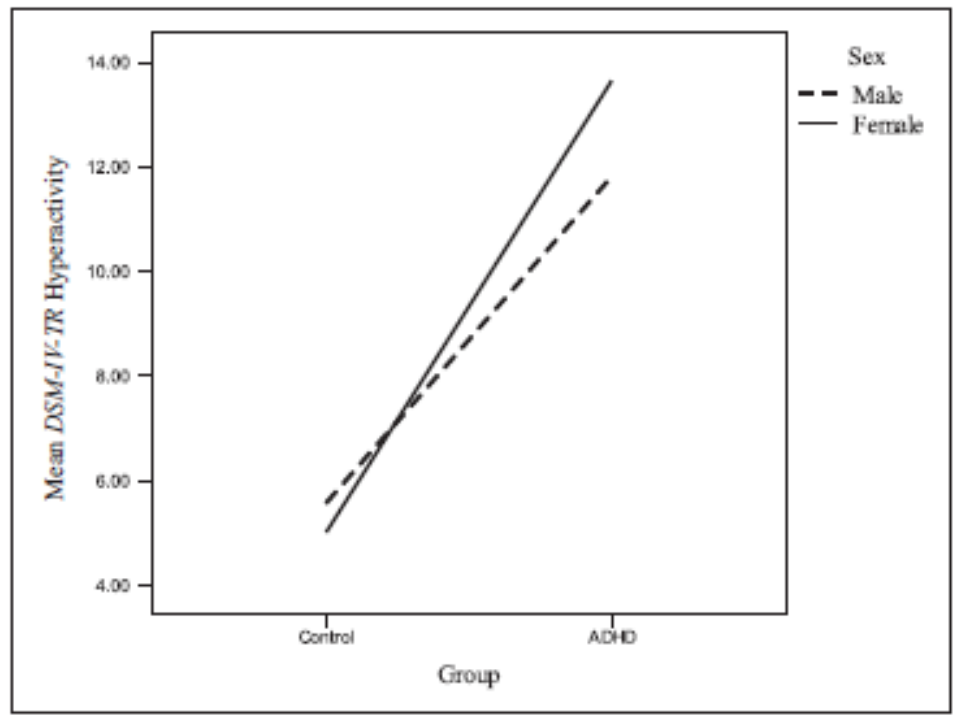

Figure 2. Comparison of hyperactivity symptoms DSM-IV-TR = Diagnostic and Statistical Manual of Mental Disorders (4th ed., text revision; APA, 2000).

\section{Comparison of Impairment Across Groups and Sex}

ANCOVA analyses indicated that a significant main effect was found for group, $F(1,869)=451.10, p<.001$, partial $\eta 2=.34$, such that participants with ADHD endorsed higher levels of impairment $(M=13.72, S D=6.31)$ than controls $(M=4.81, S D=4.20)$. A main effect was also found for sex, $F(1,869)=7.05, p=.008$, partial $\eta 2=.01$, such that women endorsed lower levels of impairment $(M=6.42, S D=6.32)$ than did men $(M=6.61, S D=5.23)$. Notably, these main effects were qualified by a significant sex by group interaction, $F(1,869)=29.80, p<.001$, partial $\eta 2=.03$. Post hoc analyses revealed a significant main effect for sex in the control group, $F(1,707)=13.21, p<.001$, partial $\eta 2=.02$, such that women endorsed lower levels of impairment $(M=$ 4.26, $S D=3.92)$ than did men $(M=5.44, S D=4.41)$. In 
contrast, a significant main effect for sex was also found for participants in the ADHD group, $F(1,161)=12.08, p=.001$, partial $\eta 2=.07$, such that women endorsed higher levels of impairment $(M=15.20, S D=6.65)$ than did men $(M=$ $12.08, S D=5.31)$. See Figure 3.

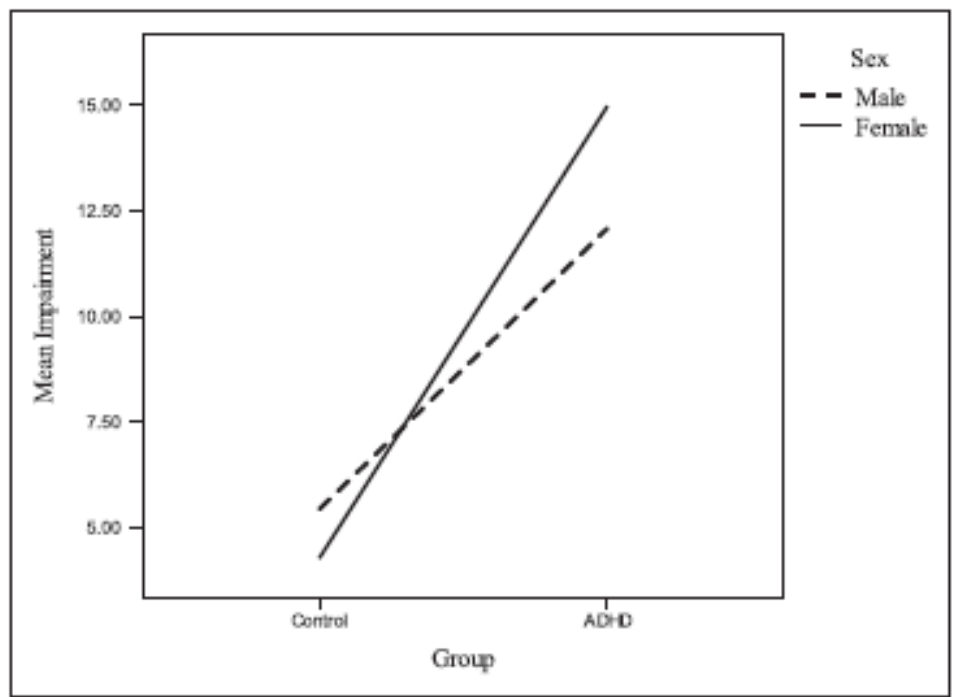

Figure 3. Comparison of impairment symptoms

Multiple analysis of covariance (MANCOVA) analyses were conducted to examine impairment items in the ADHD group (see Table 1). Analyses revealed that women with ADHD endorsed significantly higher impairment for 5 of 10 impairment items than men with ADHD. In particular, women endorsed significantly more impairment in their home life with immediate family, social activities, dating or martial relationships, educational activities, money management, and daily life activities. 
Table I. Impairment Scores for ADHD Group by Sex

\begin{tabular}{|c|c|c|c|c|c|c|c|}
\hline & \multicolumn{2}{|c|}{ Men with ADHD } & \multicolumn{2}{|c|}{$\begin{array}{c}\text { Women } \\
\text { with ADHD }\end{array}$} & \multicolumn{3}{|c|}{ MANCOVA } \\
\hline & $M$ & $S D$ & $M$ & $S D$ & $F$ & pvalue & $\eta^{2}$ \\
\hline \multicolumn{8}{|l|}{ Impairment item } \\
\hline I. Home life & 1.16 & 0.78 & 1.47 & 1.04 & 4.44 & .037 & 0.03 \\
\hline 2. Work & 1.25 & 0.79 & 1.43 & 0.96 & 1.80 & .182 & 0.01 \\
\hline 3. Social life & 1.28 & 0.87 & 1.56 & 0.98 & 3.95 & .049 & 0.03 \\
\hline 4. Community & 1.20 & 0.80 & 1.19 & 0.85 & 0.00 & .975 & 0.00 \\
\hline 5. Education & 1.90 & 0.91 & 2.36 & 0.80 & 12.31 & .001 & 0.07 \\
\hline 6. Dating & 1.22 & 0.97 & 1.46 & 1.02 & 2.38 & .125 & 0.02 \\
\hline 7. Money & 1.10 & 1.03 & 1.50 & 1.22 & 4.74 & .031 & 0.03 \\
\hline 8. Driving & 0.96 & 1.02 & 0.98 & 0.94 & 0.01 & .908 & 0.00 \\
\hline 9. Leisure & 0.96 & 0.85 & 1.18 & 0.99 & 2.10 & .149 & 0.01 \\
\hline 10. Daily life & 1.41 & 0.91 & 1.79 & 0.92 & 6.95 & .009 & 0.04 \\
\hline Overall impairment & 12.08 & 5.31 & 15.16 & 6.65 & 12.08 & .001 & 0.07 \\
\hline
\end{tabular}

164 participants included in the analysis.

\section{Regression Analyses Predicting Impairment}

Regression analyses revealed that age was a significant predictor of impairment $(\beta=.17, p=.030)$. Inattention $(\beta=.55$, $p<.001)$ and hyperactivity summary scores $(\beta=.22, p=.001)$ also accounted for unique variance in impairment. Specifically, as levels of $D S M-I V-T R$ inattention or hyperactivity increased, so did overall impairment. Finally, sex also accounted for unique variance in impairment summary scores ( $\beta=.12, p=.049$; see Table 2 ) beyond that accounted for by age, levels of inattention, and levels of hyperactivity in the ADHD group. Thus, women with ADHD report experiencing more impairment than men with ADHD even after accounting for sex differences in symptom severity.

Table 2. Linear Regression Predicting Impairment

\begin{tabular}{lccccc}
\hline Step and variable & $B$ & $S E(B)$ & $\beta$ & $\Delta R^{2}$ & $F$ for $\Delta R^{2}$ \\
\hline I Age & .28 & .13 & $.17^{*}$ & .03 & $4.80^{*}$ \\
2 DSM-IV-TR inattention & .60 & .07 & $.55^{* * 1 \% *}$ & .45 & $70.29 \%$ *o*k \\
DSM-IV-TR hyperactivity & .25 & 08 & $.22^{* * *}$ & & \\
3 Sex & 1.45 & .73 & $.12^{*}$ & .01 & $3.92^{*}$ \\
\hline
\end{tabular}

164 participants were included in the analysis. DSM-IV-TR = Diagnostic and Statistical Manual of Mental Disorders (4th ed., text revision; APA, 2000). $* p<.05$. * $p<.01$. **** $p<.001$. 


\section{DISCUSSION}

The first goal of this study was to determine whether there are sex differences in DSM-IV-TR inattention and hyperactivity symptoms in emerging adults in college with ADHD. It was hypothesized that individuals in the ADHD group would report higher levels of inattention and hyperactivity symptoms than individuals in the control group and that college men would report higher symptoms than college women. As expected, individuals in the ADHD group reported higher levels of $A D H D$ symptoms than did individuals in the control group. However, contrary to hypothesis one, sex differences were found for both inattention and hyperactivity such that college women showed higher rates than college men. These results are somewhat similar to those found by Biederman et al. (2004), but quite different than the findings of other studies (e.g., Biederman et al., 2005; DuPaul et al., 2001; Murphy \& Barkley, 1996). Specifically, Biederman and colleagues (2004) found sex differences in current DSM-IV-TR inattention scores only, whereas other studies failed to find any sex differences (Biederman et al., 2005; DuPaul et al., 2001; Murphy \& Barkley, 1996). Therefore, the current study partially replicates Biederman et al. (2004), lending some support to the notion that college women with ADHD may have higher rates of inattention than do college men with ADHD.

However, as noted previously, the current study also found sex differences in hyperactivity symptoms; these findings are divergent from all previous research in this area. This is an interesting finding considering that at younger ages boys demonstrate higher levels of hyperactivity than girls do (APA, 2000). It is possible that some over-activity among college men is considered normative, whereas any over activity among college women is seen as atypical and, therefore, the same behaviors may be perceived and rated differently. Although speculative, these results may therefore suggest that college women have higher standards for themselves in regard to behavior when completing self-report measures.

Likewise, the current study demonstrated a novel finding in terms of impairment. It was predicted that individuals in the ADHD group would report higher impairment than individuals in the control group and that college men would report higher impairment than college women. As hypothesized, individuals in the ADHD group reported more impairment than individuals in the control group. However, sex differences were found such that college women with ADHD had higher levels of impairment than do college men with ADHD.

Finally, it was hypothesized that among individuals in college with ADHD, sex would account for unique variance 
in impairment scores above and beyond variance accounted for by sex differences in levels of ADHD symptoms. This prediction was supported such that sex accounted for unique variance in impairment in the ADHD group after controlling for sex differences in ADHD symptoms. Therefore, the current data suggest that college women with ADHD self-report higher levels of impairment than do college men with ADHD even after controlling for preexisting sex differences in levels of ADHD symptoms. This is somewhat consistent with the findings of Robison et al. (2008) who found higher levels of impairment in typical adult women than men in one aspect of impairment (i.e., emotional lability). However, the current findings are contrary to other studies of sex differences in adult ADHD impairment in that previous studies found no evidence of differential rates of impairment (Biederman et al., 2005; Sobanksi et al., 2007).

The current study showed significantly higher rates of self-reported impairment in college women with ADHD than in college men with ADHD in the following areas: home life, social life, education, money, daily life, and overall impairment. In addition, there was a trend in the same direction for dating. On the other hand, there were domains of impairment that did not show differential rates in college men and women. Specifically, no statistically significant sex differences were found for work, community living skills, driving, or leisure activities. Therefore, as demonstrated in Robison et al. (2008) and in the current study, it is possible that there are differential rates of impairment in some domains but not others. The domains of impairment in which college women with ADHD had significantly higher rates than college men with ADHD may have common features that other of functioning domains do not share. For example, young women with ADHD rated themselves as more impaired in home, social, and daily life than did young men with ADHD. Given the differential value men and women place on maintaining close social ties and relationships (e.g., Block, 1983), it is reasonable to speculate that the symptoms of ADHD may be more distressing to young women than men. Young men may perceive social/ relational deficits as less impairing than young women as a result of differential socialization.

Alternatively, a phenomenon referred to as stereotype threat (Steele \& Aronson, 1995) could be contributing to the observed sex differences in some domains of impairment. Specifically, in the domains of education and money, college women in the current study were found to report higher rates of impairment. One possible explanation for this difference is that young women's expectations for their own performance are negatively influenced by societal expectations. In this case, it is feasible that young women perceive their ability to perform academic 
and financial tasks as poor because of stereotypes suggesting decreased ability of women and of individuals with ADHD.

This threat has been shown to decrease expectations and performance for many different groups of people on many different types of tasks (e.g., Catsambis, 1994; O'Brien \& Crandall, 2003; Stone, Lynch, Sjomeling, \& Darley, 1999) and therefore may help explain the findings in the current study.

In an attempt to understand the current findings, the related concept of positive illusory bias (PIB) also deserves mention. PIB refers to individuals perceiving their abilities as more positive than what they actually are and this bias has been shown to exist in children with ADHD (Hoza, Pelham, Dobbs, Owens, \& Pillow, 2002). With regard to ADHD, researchers are conflicted as to whether this phenomenon is adaptive since individuals with ADHD are often more likely to experience academic, social, and behavior difficulties in the classroom and elsewhere (Owens, Goldfine, Evangelista, Hoza, \& Kaiser, 2007). Regardless, both boys and girls with ADHD appear to evidence PIB to a similar degree (Hoza et al., 2004, Owens \& Hoza, 2003). Notably, no studies to date have examined whether the equality across sex in PIB extends beyond childhood. Although speculative, the results of the current study could suggest that college men with ADHD continue to demonstrate PIB whereas college women may be more accurate raters of their levels of impairment. This is keeping with some prior research which has, in fact, suggested that PIB may continue to influence social schemas, such as rejection sensitivity (Downey, Khouri, \& Feldman, 1997), in young men with ADHD, whereas evidence for this phenomenon in women is lacking (Canu \& Carlson, 2007). Therefore, a combination of stereotype threat and PIB may be influencing women's self-reported impairment.

On the other hand, in domains where no sex differences emerged it could be that both college women and men with ADHD demonstrate some lack of insight. For example, no sex differences were found in the domain of driving. It is possible that both college men and women with ADHD overestimated their driving ability, as driving has been shown to be impaired in individuals with ADHD (Barkley, Guevremont, Anastopoulos, DuPaul, \& Shelton, 1993; Murphy \& Barkley, 1996), but self-reported driving ability by all adults tends to be overly positive (Lajunen, Corry, Summala, \& Hartley, 1997). Moreover, both college men and women with ADHD rated themselves as the least impaired in the domains of driving, leisure, and community living where no sex differences emerged. It is possible that neither young men nor women feel particularly affected by their ADHD symptoms in these domains and therefore have equally low rates of impairment. 


\section{LIMITATIONS AND FUTURE DIRECTIONS}

A primary limitation of this study is that participants were not asked about current or previous treatment with therapy or medication. It is suggested that researchers take this into consideration for future studies as individuals who have received treatment may have improved functioning and lower levels of symptoms. Objective measures of potential impairment such as formal records of college grade point average and entrance exam scores were not collected. Furthermore, given that the sample was $85 \%$ European American, it will be important to determine whether the results generalize to emerging adults from different ethnic/racial backgrounds. Along these lines, the current sample study was comprised of college students who may be, generally speaking, higher functioning than and imperfectly representative of their same-age peers with ADHD who are not enrolled in college. Therefore, this is another important area for future research.

Finally, it is a limitation that individuals who met ADHD criteria based on self-report rating scales, in the absence of collateral reports, were included in the ADHD group in addition to individuals who reported having a diagnosis. Although the literature suggests that the ideal assessment of ADHD should include self-report rating scales and collateral report rating scales from significant others (Mash \& Barkley, 2003), collateral data were only collected from approximately $10 \%$ of the sample because of low return rates. For individuals who were previously diagnosed with ADHD, it was not known whether evidence-based assessment tools (e.g., self-report and collateral report rating scales) were used. In future studies, researchers are encouraged to continue to attempt to collect collateral data for diagnostic purposes.

\section{CONCLUSION}

This study is one of only a few studies to examine possible sex differences in ADHD symptoms and ADHD-related impairment in young adults in college with ADHD. The findings are unique in that sex differences were found in levels of ADHD symptoms, both inattention and hyperactivity, and impairment such that college women had higher levels of symptoms and impairment. This is largely divergent from previous studies that have found few or no sex differences in adult ADHD. Due to some methodological limitations and the novel findings of the current study, it is important to replicate these findings before firm conclusions can be drawn. However, this study lends preliminary support to the notion that college men and women are differentially affected by ADHD. 


\section{REFERENCES}

American Psychiatric Association (APA). (2000). Diagnostic and statistical manual of mental disorders (4th ed., text rev.). Washington, DC: Author.

Barkley, R. A., Guevremont, D. C., Anastopoulos, A. D., DuPaul, G. J., \& Shelton, T. L. (1993). Driving-related risks and outcomes of attention deficit hyperactivity disorder in adolescents and young adults: A 3- to 5-year follow-up survey. Pediatrics, 92, 212-218.

Barkley, R. A., \& Murphy, K. R. (2005). Attention-deficit/ hyperactivity disorder: A clinical workbook (3rd ed.). New York, NY: Guilford.

Barkley, R. A., Murphy, K. R., \& Kwasnik, D. (1996). Psychological adjustment and adaptive impairments in young adults with ADHD. Journal of Attention Disorders, 1, 41-54.

Bauermeister, J. J., Shrout, P. E., Chavez, L., Rubio-Stipec, M., Ramirez, R., Padilla, L., ... Canino, G. (2007). ADHD and gender: Are risks and sequela of ADHD the same for boys and girls? Journal of Child Psychology and Psychiatry, 48, 831-839.

Biederman, J., Faraone, S. V., Mick, E., \& Spencer, T. (1995). High risk for attention deficit hyperactivity disorder among children of parents with childhood onset of the disorder: A pilot study. American Journal of Psychiatry, 152, 431-435.

Biederman, J., Faraone, S. V., Monuteaux, M. C., Bober, N., \& Cadogen, E. (2004). Gender effects on attention-deficit/hyperactivity disorder in adults, revisited. Biological Psychiatry, 55, 692-700.

Biederman, J., Faraone, S. V., Spencer, T., Mick, E., Monuteaux, M. C., \& Aleardi, M. (2006). Functional impairments in adults with selfreports of diagnosed ADHD: A controlled study of 1001 adults in the community. Journal of Clinical Psychiatry, 67, 524-540.

Biederman, J., Kwon, A., Aleardi, M., Chouinard, V., Marino, T., Cole, H., ... Faraone, S. V. (2005). Absence of gender effects on attention deficit hyperactivity disorder: Findings in nonreferred subjects. American Journal of Psychiatry, 162, 1083-1089.

Block, J. H. (1983). Differential premises arising from differential socialization of the sexes: Some conjectures. Child Development, $54,1335-1354$.

Canu, W. H., \& Carlson, C. L. (2003). Differences in heterosocial behavior and outcomes of ADHD-symptomatic subtypes in a college sample. Journal of Attention Disorder, 6, 123-133. 
Canu, W. H., \& Carlson, C. L. (2007). Rejection sensitivity and social outcomes of young adult men with ADHD. Journal of Attention Disorders, 10, 261-275.

Catsambis, S. (1994). The path to math: Gender and racial-ethnic differences in mathematics participation from middle school to high school. Sociology of Education, 67, 199-215.

de Graaf, R., Kessler, R. C., Fayyad, J., ten Have, M., Alonso, J., Angermeyer, M., . . . Posada-Villa, J. (2008). The prevalence and effects of adult attention-deficit/hyperactivity disorder (ADHD) on the performance of workers: Results from the WHO World Mental Health Survey Initiative. Occupational and Environmental Medicine, 65, 835-842.

Downey, G., Khouri, H., \& Feldman, S. I. (1997). Early interpersonal trauma and later adjustment: The mediational role of rejection sensitivity. In D. Cicchetti \& S. L. Toth (Eds.), Developmental perspectives on trauma: Theory, research, and intervention (pp. 85-114). Rochester, NY: University of Rochester Press. DuPaul, G. J., Schaughency, E. A., Weyandt, L. L., Tripp, G., Kiesner, J., Ota, K., \& Stanish, H. (2001). Self-report of ADHD symptoms in university students: Cross-gender and cross-national prevalence. Journal of Learning Disabilities, 34, 370-379.

Faraone, S. V., \& Biederman, J. (2005). What is the prevalence of adult ADHD? Results of a population screen of 966 adults. Journal of Attention Disorders, 9, 384-391.

Faraone, S. V., Biederman, J., Feighner, J.A., \& Monuteaux, M. C. (2000). Assessing symptoms of attention deficit hyperactivity disorder in children and adults: Which is more valid? Journal of Consulting and Clinical Psychology, 68, 830-842.

Fedele, D. A., Hartung, C. M., Canu, W. H., \& Wilkowski, B. (in press). Potential symptoms of ADHD for emerging adults. Journal of Psychopathology and Behavioral Assessment.

Fischer, M., Barkley, R. A., Edelbrock, C. S., \& Smallish, L. (1990). The adolescent outcome of hyperactive children diagnosed by research criteria: II. Academic, attentional, and neuropsychological status. Journal of Consulting and Clinical Psychology, 58, 580-588.

Gathje, R. A., Lewandowski, L. J., \& Gordon, M. (2008). The role of impairment in the diagnosis of ADHD. Journal of Attention Disorders, 11, 529-537.

Gittelman, R., Mannuzza, S., Shenker, R., \& Bonagura, N. (1985). Hyperactive boys almost grown up. I. Psychiatric status.

Archives of General Psychiatry, 42, 937-947. 
Gordon, M., Antshel, K., Faraone, S., Barkley, R., Lewandowski, L., Hudziak, J. J., . . . Cunningham, C. (2008). Symptoms versus impairment: The case for respecting DSM-IV's criterion D. Journal of Attention Disorders, 9, 465-475.

Hartung, C. M., \& Widiger, T. A. (1998). Gender differences in the diagnosis of mental disorders: Conclusions and controversies of the DSM-IV. Psychological Bulletin, 123, 260-278.

Heiligenstein, E., Conyers, L. M., Berns, A. R., \& Miller, M. A. (1998). Preliminarynormative data on DSM-IV attention deficit hyperactivity disorder in college students. Journal of American College Health, 46, 185-188.

Hermens, D. F., Williams, L. M., Lazzaro, I., Whitmont, S., Melkonian, D., \& Gordan, E. (2004). Sex differences in adult ADHD: A double dissociation in brain activity and autonomic arousal. Biological Psychology, 66, 221-233.

Hoza, B., Gerdes, A. C., Hinshaw, S. P., Arnold, E. L., Pelham, W. E., Molina, B. S., . . . Wigal, T. (2004). Self-perceptions of competence in children with ADHD and comparison children. Journal of Consulting and Clinical Psychology, 72, 382-391.

Hoza, B., Pelham, W. E., Dobbs, J., Owens, J. S., \& Pillow, D. R. (2002). Do boys with attention deficit/hyperactivity disorder have positive illusory self-concepts? Journal of Abnormal Psychology, 111, 268-278.

Kessler, R. C., Adler, L., Barkley, R. A., Biederman, J., Conners, C. K., Demler, O., ... Zaslavsky, A. M. (2006). The prevalence and correlates of adult ADHD in the United States: Results from the National Comorbidity Survey Replication. American Journal of Psychiatry, 163, 716-723.

Kessler, R. C., Lane, M., Stang, P. E., \& Van Brunt, D. L. (2009). The prevalence and workplace costs of adult attention deficit hyperactivity disorder in a large manufacturing firm. Psychological Medicine, 39, 137-147.

Lajunen, T., Corry, A., Summala, H., \& Hartley, L. (1997). Impression management and self-deception in traffic behaviour inventories. Personality and Individual Differences, 22, 341-353.

Lewandowski, L. J., Lovett, B. J., Codding, R. S., \& Gordon, M. (2008). Symptoms of ADHD and academic concerns in college students with and without ADHD diagnoses. Journal of Attention Disorders, 12, 156-161. 
Malloy-Diniz, L., Fuentes, D., Leite, W. B., Correa, H., \& Bechara, A. (2007). Impulsive behavior in adult with attention deficit/hyperactivity disorder: Characterization of attentional, motor and cognitive impulsiveness. Journal of the International Neuropsychological Society, 13, 693-698.

Manshadi, M., Lippman, S., O’Daniel, R. G., \& Blackman, A. (1983). Alcohol abuse and attention deficit disorder. Journal of Clinical Psychiatry, 44, 379-380.

Manuzza, S., Klein, R. G., Bessler, A., Malloy, R., \& LaPadula, M., (1993). Adult outcome of hyperactive boys. Educational achievement, occupational rank, and psychiatric status. Archives of

General Psychiatry, 50, 565-576.

Mash, E. J., \& Barkley, R. A. (2003). Child psychopathology. New York, NY: Guilford.

Murphy, K. R., \& Barkley, R. A. (1996). Prevalence of DSM-IV symptoms of ADHD in adult licensed drivers: implications for clinical diagnosis. Journal of Attention Disorders, 1, 147-161.

Murphy, K. R., Barkley, R. A., \& Bush, T. (2001). Executive functioning and olfactory identification in young adults with attention deficit-hyperactivity disorder. Neuropsychology, 15, 211-220.

O'Brien, L., \& Crandall, C. (2003). Stereotype threat and arousal: Effects on women's math performance. Personality and Social Psychology Bulletin, 29, 782-789.

Owens, J. S., Goldfine, M. E., Evangelista, N. M., Hoza, B., \& Kaiser, N. (2007). A critical review of self-perceptions and the positive illusory bias in children with ADHD. Clinical Child and Family Psychology Review, 10, 335-351.

Owens, J. S., \& Hoza, B. (2003). The role of inattention and hyperactivity/impulsivity in the positive illusory bias. Journal of Consulting and Clinical Psychology, 71, 680-691.

Rasmussen, K., \& Levander, S. (2009). Untreated ADHD in adults: Are there sex differences in symptoms, comorbidity, and impairment? Journal of Attention Disorders, 12, 353-360.

Robison, R. J., Reimherr, F. W., Marchant, B. K., Faraone, S. V., Adler, L. A., \& West, S. A. (2008). Gender differences in 2 clinical trials of adults with attention-deficit/hyperactivity disorder: A retrospective data analysis. Journal of Clinical Psychiatry, 69, 213-221. 
Rucklidge, J. J. (2008). Gender differences in ADHD: Implications for psychosocial treatments. Expert Reviews of Neurotherapeutics, 8, 643-655.

Schwanz, K. A., Palm, L. J., \& Brallier, S. A. (2007). Attention problems and hyperactivity as predictors of college grade point average. Journal of Attention Disorders, 11, 368-373.

Seidman, L. J., Doyle, A., Fried, R., Valera, E., Crum, K., \& Matthews, L. (2004). Neuropsychological function in adults with attention-deficit/hyperactivity disorder. Psychiatric Clinics of North America, 27, 261-282.

Sobanski, E., Bruggemann, D., Alm, B., Kern, S., Deschner, M., Schubert, T., ... Rietschel, M. (2007). Psychiatric comorbidity and functional impairment in a clinically referred sample of adults with attention-deficit/hyperactivity disorder (ADHD). European Archives of Psychiatry and Clinical Neuroscience, 257, 371-377.

Steele, C. M., \& Aronson, J. (1995). Stereotype threat and intellectual test performance of African Americans. Journal of Personality and Social Psychology, 69, 797-811.

Stone, J., Lynch, C. I., Sjomeling, M., \& Darley, J. M. (1999). Stereotype threat effects on Black and White athletic performance.

Journal of Personality and Social Psychology, 77, 1213-1227.

Weiss, G., \& Hechtman, L. T. (1993). Hyperactive children grown up: $A D H D$ in children, adolescents, and adults. New York, NY: Guilford.

Weiss, G., Hechtman, L. T., Milroy, T., \& Perlman, T. (1985). Psychiatric status of hyperactives as adults: A controlled 15-year follow-up of 63 hyperactive children. Journal of the American Academy of Child Psychiatry, 24, 211-220.

Wender, P. H. (1987). The hyperactive child, adolescent, and adult: Attention deficit disorder through the lifespan. New York, NY: Oxford University Press. 